\title{
CONFLITOS E INTENÇÕES NARRATIVAS ENTRE FICÇÃO E REALIDADE: REFLEXÕES SOBRE CONCEPÇÕES SOCIAIS E DE GÊNERO EM "O QUE É ISSO COMPANHEIRO?"1
}

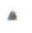

Maria do Socorro Gomes de Araújo

Domingos Leite Lima Filho ${ }^{3}$

\begin{abstract}
Não soube na hora, nem jamais fiquei sabendo, quem foi o primeiro a largar a corda. Não estou preparado para admitir a hipótese de que tenha sido eu. Mas cada um de nós afirma não ter sido o primeiro. O que é seguro é que se não houvéssemos nos dividido nosso peso conjunto teria trazido o balão de volta ao solo um quarto do declive abaixo $e$ poucos segundos depois, quando o vento se acalmou. Mas, como disse, não havia equipe, não havia plano, nenhum compromisso a ser quebrado. [...] Suspenso a alguns metros de altura, sobre a escarpa em Chilternhills, nosso grupo dramatizou o conflito ancestral e sem resposta: nós ou eu. Alguém disse eu e não havia mais nada a ganhar dizendo nós. De maneira geral, a gente exerce o bem quando faz sentido. Uma sociedade boa é aquela que dá sentido a essa bondade. De um momento para o outro, pendurados embaixo do cesto, nós estávamos em uma sociedade em pedaços, estávamos nos desintegrando. De um momento para o outro, a escolha sensata era cuidar de si. O menino não era meu filho e eu não iria morrer por ele ... a questão estava decidida: não havia lugar para altruísmo. Bondade não fazia sentido. (lan McEwan)
\end{abstract}

Algumas características do filme "O que é isso companheiro?" são analisadas no presente texto. Dado o seu caráter sintético, não se pretende aqui uma discussão exaustiva e aprofundada. Nossos objetivos são o de fazer uma contextualização da época, bem como o de situar algumas questões para a reflexão e o debate acerca das concepções sociais e de gênero presentes na obra.

\section{O filme: produção hollywoodiana na indústria de} entretenimento nacional

O filme, de 1997, é uma co-produção de Columbia Pictures e Sony Corporation, com distribuição da Colúmbia Pictures do Brasil, baseada no livro homônimo de Fernando Gabeira. O filme é apresentado por Luci e Carlos Barreto, direção de Bruno Barreto, fotografia de Félix Monti (o mesmo de O

1 Texto apresentado ao evento "Representações de Gênero no Cinema", PPGTE - CEFET-PR, Curitiba, 16 a 18.07.2003.

2 Fotógrafa e Historiadora, Pesquisadora de manifestações de raízes culturais brasileiras.

3 Doutor em Educação (UFSC). Professor do Programa de Pós-Graduação em Tecnologia do CEFET-PR. 
Quatrilho), roteiro de Leopoldo Serran, direção de arte Marcos Flaksan, trilha musical Stewart Coperland e montagem Isabelle Rathery. Com a participação do ator norte-americano Alan Arkin, no papel do embaixador Charles Elbrick (com grande destaque pela crítica de um "show de interpretação"), acompanhado de um elenco nacional bem global: Pedro Cardoso (Paulo, Fernando Gabeira), Fernanda Torres (Maria, Vera Silvia), Claudia Abreu (Renée, Vera Silvia), Luis Fernando Guimarães e outros.

"O que é isso companheiro?" surge em um contexto de dinamização da atividade comercial na industria cinematográfica nacional. No próprio decorrer das filmagens, a mídia destacou com grande importância a produção, preparando o seu futuro "sucesso de bilheteria", aspecto inovador se tomarmos como referência outras produções nacionais do gênero.

Defendido publicamente pelo diretor Bruno Barreto como uma ficção, em verdade o filme não escapa de oferecer sua versão intencionada da história ocorrida no ano de 1969. Esta afirmação/posição de Barreto é indefensável, na medida em que o roteiro é todo desenvolvido em paralelo com a história passada, estabelecendo correspondência em data, personagens, nomes e, inclusive, em uma cena na qual aparece sob o retrato do personagem (o "fictício" Paulo) o seu nome real, Fernando Gabeira. Por essas e outras, de fato, o filme acaba fugindo da declarada característica ficcional e assume a real posição de oferecer uma versão própria e intencional da história.

Adorno e Horkheimer, desde a década de 1940, em "Dialética do esclarecimento", já destacavam a importância da indústria cultural na elaboração e manutenção das hierarquias e hegemonias. Assim, é possível entender a produção de entretenimento pela indústria cinematográfica como uma dimensão importante da produção social do imaginário nas sociedades contemporâneas. Nesse aspecto, a indefinição sobre o estatuto, o sentido e os limites da realidade e da ficção, ou seja, a pasteurização da história e seus deslocamentos entre história social e historia cultural, é um dos ingredientes fundamentais do ideário neoliberal pós-moderno (MORAES, 1994). Como afirmou Jameson acerca da história de nossos tempos, é fundamental a destacar a importância capital da produção de um sistema de signos mediante os quais cotidianamente conduzimos nossas ações e a nós mesmos explicamos o conteúdo e significado de nosso ser e devir (JAMESON, 1988).

Conforme Freire, "a insistência na discussão da questão documento/ficção deve-se ao fato de que não entendemos o livro [O que é isso companheiro?, de Gabeira] como uma peça apenas ou fundamentalmente narcísica, mas como um documento de adesão à transição conservadora que já se anunciava no Brasil no final dos anos setenta quando o livro foi lançado" (FREIRE, 1997, p. 157).

O filme, ao buscar um caminho "equilibrado" e "politicamente correto", apresenta uma narrativa supostamente "isenta" e "desideologizada" - em conformidade com a transição conservadora e o ideário neoliberal - e acaba efetivamente produzindo uma versão distorcida da história. Pode-se argumentar, que o cineasta tem a liberdade de fazê-lo. No entanto, ao proceder assim, Barreto não foi fiel aos preceitos básicos da ficção, qual seja, a ruptura total com elementos da realidade que se pretende ficcionar. Ao contrário, ao mesclar cenas, tomadas, imagens documentais e inclusive o nominamento real 
de personagens, com elementos de pura ficção, a obra cinematográfica produz, efetivamente, uma versão que direciona para uma falsificação da realidade.

O CONTEXTO: CONTESTAÇÃO E AÇÃO REVOLUCIONÁRIA COMO ESPÍRITO DA ÉPOCA

Em que quadro de referência podemos compreender o surgimento e a ação dos movimentos e organizações de luta armada urbana e ou de guerrilha no campo no Btasil dos anos de 1960? Para tanto, é necessário observar duas dimensões que estão interligadas. Uma no plano interno e outra no plano internacional.

\section{QUANTO A PRIMEIRA:}

No inicio dos anos de 1960 o Brasil se viu mergulhado em uma crise econômica que teve acirramento no plano interno pela incapacidade do Estado populista de atender às reivindicações populares por reformas sociais. Foi nesse período que cresceu a mobilização do proletariado e das massas urbanas e camponesas por reformas de base (agrária, solo urbano, direitos sociais, universalização de saúde e educação, salários reais, controle sobre capitais estrangeiros etc). As elites do poder nacional em acordo e colaboração com o capital internacional trataram de rearticular o seu projeto de continuidade de poder e para tanto o recurso à interrupção da ordem constitucional não foi descartado, o que representa uma persistência na tradição secular golpista dessas elites em nosso pais.

\section{QUANTO A SEGUNDA:}

Temos aqui uma série de fatores conexos:

1 - O inicio da década de 1960 marca uma interrupção da estabilidade do modelo econômico e o enfraquecimento da supremacia norteamericana iniciada no pós-guerra de 1945, durante o qual ocorreu o absoluto domínio econômico, ideológico e cultural dos EUA.

2 - Durante este período também ocorreu o sub-imperialismo da URSS articulado ao imperialismo norte-americano (Guerra Fria como ordenamento formal de um modelo de submissão real).

3 - Ao final dos anos de 1950 uma maré de lutas de libertação nacional varreu a África de norte a sul, parte do continente asiático e países da América Central e Caribe.

4 - Ao início dos anos de 1960, em quatro países as revoltas foram guerras de libertação sumariamente vitoriosas (China, Vietnã, Argélia e Cuba), com características particulares, mas com quatro diretrizes gerais coincidentes: a) impuseram sua tomada de poder às grandes potências internacionais pela determinação com a qual buscaram sua autonomia política; b) proclamaram a importância do poder estatal como requisito para a transformação social; c) defenderam a modernidade como projeto de desenvolvimento 
nacional; d) se afirmavam como a vanguarda do progresso histórico.

5 - Em 1960, dezesseis países africanos tornaram-se independentes e em 1963 foi fundada a Organização da Unidade Africana, dando passo importante para que a descolonização ou o seu equivalente se concretizasse em quase todo o mundo.

6 - Na metade da década de 1960, efetivamente, o sentimento de libertação e a luta contra a ordem estabelecida haviam se espalhado pelo mundo, com uma forca muito forte, um imaginário de uma nova ordem possível, um espírito de época que dominava o mundo. Os EUA (e a própria URSS, como seu correspondente solidário da dinâmica da guerra fria) e as elites do capital internacional surpreenderam-se com a força deste movimento e temeram por seus impactos e desdobramentos.

7 - No ano de 1968 havia revoluções vitoriosas de povos tidos como subdesenvolvidos e ao mesmo tempo questionava-se o regime soviético, enfim, o modelo guerra fria (exemplos: Primavera de Praga, 1968; revolução cultural proletária da China, 1966; a contracultura e o movimento hippie; as manifestações contra a guerra no Vietnã). Em fevereiro de 1968, Martin Luther King foi assassinado. Em abril iniciam-se os movimentos da revolução cultural e política que culminam com o maio de 1968, na França e em todo o mundo. Duas questões eram comuns e centrais:

a) a oposição à hegemonia dos EUA.

b) o profundo desapontamento com a velha e tradicional esquerda e seus métodos e táticas conciliatórias (WALLERSTEIN, 2002).

É observando estas duas dimensões articuladamente, em âmbito nacional e internacional, que podemos entender os acontecimentos políticos e sociais que marcaram o Brasil nos anos de 1960. Neste aspecto, é importante destacar dois momentos - o do golpe militar de 1964 e o do endurecimento do regime, em 1968.

Com efeito, o golpe militar de 1964 foi uma articulação das elites nacionais - na sua reação aos movimentos por reformas sociais - e também se insere na dinâmica mais ampla de reação do imperialismo norte-americano às lutas nacionais de libertação que marcaram o mundo naquele início de década (veja-se, por exemplo, a grande influencia que a revolução cubana exerceu, e de certo modo segue exercendo, sobre o imaginário das lutas sociais em toda a América Latina). Os EUA fortaleceram sua ação imperialista no continente mediante acordos de "cooperação" (tipo Aliança para o Progresso e outros) e/ou intervenções políticas e militares diretas ou indiretas. A ideologia da segurança nacional se assentava na lógica da guerra fria e na necessidade de contra-ataque para a manutenção da hegemonia. A reação imperialista contou com atos de força dos EUA em acordo com elites locais onde foi possível, sobretudo na América Latina - iniciando-se em 1964, no Brasil e prosseguindo com intervenções e estabelecimento de ditaduras no Chile e Uruguai (1973) e na Argentina (1976). 
O período de 1968 está sintonizado no plano internacional aos movimentos culturais e políticos (em âmbito nacional temos como correlatos, embora com razões específicas, o tropicalismo, O CPC, MPC, as ligas camponesas, o MEB etc). A dinâmica internacional e os interesses locais produziram o fechamento do regime e a impossibilidade de articulação política e social da sociedade civil pela proibição de funcionamento de suas organizações (sindicatos, partidos políticos, organizações comunitárias etc) e acabaram contribuindo para a eclosão da luta armada. Por outro lado, como dissemos anteriormente, os movimentos vitoriosos de revolta internacional também influenciaram sobre uma nova tática de ação das esquerdas, que repudiavam tanto a lógica bipolar da guerra fria quanto os métodos convencionais da esquerda (articulados à social democracia européia, não aplicáveis à realidade concreta dos países da periferia do capitalismo), bem como expressavam sua crítica à tática dos partidos de orientação comunista, vinculados à burocracia soviética.

Em síntese, o contexto no qual emerge e se desenvolve a luta armada no Brasil ao final dos anos de 1960, respeitadas as particularidades locais, está inserido na dinâmica internacional caracterizada pela contestação e ação revolucionária contra a ordem internacional estabelecida, movimento no qual se estabelecem confrontos com os valores e hegemonias políticas, econômicas e culturais dominantes. Por sua vez, a reação do regime militar e das elites nacionais aos movimentos urbanos e rurais de contestação, em particular aos grupos que aderiram à luta armada, mediante perseguição política, tortura e aniquilamento físico e político, também se insere na questão da manutenção do poder interno, porém articula-se com o movimento mais amplo de (re)organização da hegemonia em conflito mundial, no qual os EUA como nação hegemônica jogam papel preponderante.

\section{Ficção ou realidade: Compromisso com a Historia (ou estória) e limites éticos do entretenimento}

O roteiro geral do filme sustenta-se em três pilares que, se confrontados com a história real, são bastante polêmicos e perigosos em razão de que podem oferecer à juventude de hoje uma visão diversa e, sobretudo distorcida, do papel político e social desempenhado pela juventude na geração dos anos 60 e 70 em nosso país. Conforme Vera Silvia Araújo Magalhães, a versão cinematográfica produz uma visão equivocada daquilo que a juventude da época defendia: "nós não éramos uns ingênuos, ao contrário, a gente estudava desde os teóricos mais evidentes, como Marx, Engels, até Kant. Líamos Caio Prado Júnior, Vanderley Guilherme [...] a geração de 1969 lutava por uma ética, uma estética que continua até agora" (MAGALHÃES, p. 63 e ss.).

Um dos pilares referidos é a absolvição da ditadura. De fato, subliminarmente, o filme desvincula a ação dos torturadores de qualquer ação mais sistêmica do aparelho de Estado, pelo "esquecimento" deste último (as forças armadas, o aparato da ditadura, a submissão à ordem econômicopolítica internacional protagonizada pelos EUA). A tortura, então, é apresentada como atitude /decisão individual de seus praticantes, os 
torturadores, que se vêm mergulhados, no filme, em um drama de consciência, entre a ação "incômoda", porém necessária da tortura, e o seu lado "benéfico", de resgatar jovens ingênuos desencaminhados por velhos lobos seguidores de ideologias nocivas ao nosso país. Os estereótipos traçados pelo filme mostram jovens revolucionários ingênuos e manipulados por velhas raposas autoritárias desprovidas de valores éticos e nacionais (Jonas e Toledo). Os torturadores são apresentados como funcionários corretos em defesa da ordem nacional. Quanto ao embaixador, seu comportamento de gentleman e de homem culto e elegante se sobrepõe, no estereótipo, à sua função de representante oficial de uma nação imperialista. Ademais, os personagens populares (gente do povo, como uma dona de casa, um padeiro, um pintor de paredes), quando surgem em cena, demonstram sempre uma atitude colaborativa com as forças da ordem. Até mesmo um taxista, que expressa certo júbilo com o seqüestro, não o deixa de classificar como coisa de arrojados lunáticos, assemelhando os seqüestradores a cosmonautas.

Quanto ao revolucionário Jonas, comandante do seqüestro, o filme lhe atribui um perfil de totalmente depreciativo. Assim, o filme produz o que Franklin Martins chama de "a segunda morte de Jonas": "Jonas, o guerrilheiro que comandou o seqüestro do embaixador norte-americano morreu duas vezes: uma acabou com seu corpo, a outra quer suprimir sua alma". De acordo com Martins, "a segunda morte de Jonas é mais recente. Está acontecendo, com estardalhaço, no filme $\mathrm{O}$ que é isso companheiro?. Não se trata de uma morte física, mais de uma execução moral. Jonas é apresentado ao mundo inteiro como um monstro, um primata, um boçal, um desequilibrado, quase um psicopata". E pergunta, terá o Jonas do filme algo a ver com o Jonas da realidade? Pela sua convivência na própria ação com Jonas, Martins ${ }^{4}$ conclui: "posso assegurar que o Jonas do filme é um insulto ao Jonas da vida real" (MARTINS, p. 119).

O papel de protagonista desempenhado pelo personagem Paulo no filme de Barreto, ou pelo mesmo Gabeira em seu próprio livro, assume uma estatura de centralidade e importância que não correspondem ao desempenhado efetivamente por Fernando Gabeira na história do seqüestro. Daniel Aarão Reis Filho, em seu artigo "Versões e ficções: a luta pela apropriação da memória" observa: "a visão crítica do período, amadurecida coletivamente no longo exílio, é retrospectivamente localizada no fogo mesmo dos acontecimentos, concentrando-se no personagem principal. E, assim, Gabeira - guerrilheiro ressurge descolado da ingenuidade ambiente, reescrito pelo autor com uma superconsciência das tragédias que haveria de vir." (REIS, p. 101).

Além do mais, a falsificação da realidade também se vincula à

4 Franklin Martins, jornalista, idealizou e participou da ação de seqüestro ao Embaixador norteamericano Charles Elbrick, realizada entre 4 e 7 de setembro de 1969, sendo 0 redator do manifesto assinado pela Aliança Libertadora Nacional e Movimento Revolucionário 8 de outubro - MR8, divulgado amplamente à nação pelas redes de televisão e grandes jornais, em atendimento à solicitaçăo dos seqüestradores, que além disso também estabeleceram a condição de libertação de 15 prisioneiros políticos e sua extradição para o México, condições estas atendidas pela ditadura, após o que o embaixador foi libertado. 
fragilização do feminino produzida pelo filme. Isso é feito especialmente com relação à verdadeira Vera Sílvia e seus personagens. O papel real desempenhado por esta militante revolucionária é tão denso que o diretor se concede o direito de dividi-lo em dois personagens: um, doce, meigo, frágil, de certo modo ingênuo, prestativo e doméstico que lava a roupa do embaixador e cuida maternalmente de seu ferimento (Renée, representado por Claúdia Abreu); outro, duro, frio, calculista, com estereótipo masculinizado ("sargenta"), Maria (representado por Fernanda Torres). Será isso, um mero recurso cinematográfico, ou uma marca do viés de gênero?

De fato, aqui se coloca o debate entre a razão ou a emoção, como estereótipos do comportamento e ação do feminino. A reflexão de Ridenti é esclarecedora quanto a esta questão: "Vera Silvia descobriu o esquema falho de proteção ao embaixador, mas jamais se sujeitou a dormir com o chefe da segurança do embaixador como aparece no filme. $O$ diretor assume essa "liberdade poética" para dar mais dramaticidade à história, e mostra depois a menina frágil ligando para o pai, em busca de conforto, sem poder contar-lhe o ocorrido. O cineasta é livre para fazer o que quiser, mas sua versão ficcional é uma injustiça não só com a verdadeira Vera Silvia, mas principalmente com as mulheres guerrilheiras, precursoras do feminismo no Brasil." (RIDENTI, p.23).

\section{Referências bibliográficas}

ADORNO, Theodor e HORKHEIMER, Max. Dialética do esclarecimento. Rio de Janeiro: Jorge Zahar., 1985.

FREIRE, Alípio. Pela porta dos fundos. In. REIS FILHO, Daniel Aarão et alli. Versões e ficções: o seqüestro da história. São Paulo: Fundação Perseu Abramo, 1997.

JAMESON, Fredric. The ideologies of theory. London: Routledge, 1988.

MARTINS, Franklin. As duas mortes de Jonas. In. REIS FILHO, Daniel Aarão et alli. Versões e fiç̧ões: o seqüestro da história. São Paulo: Fundação Perseu Abramo, 1997. McEWAN, lan. Nós ou Eu (Enduring Love). Publicado na Folha de São Paulo, Caderno Mais, 19.10.97.

MORAES, Maria Célia M. História, narrativa e interpretações: aproximações ao pensamento de Fredric Jameson. Relatório de Pesquisa CAPES-PICD, Nottingham, 1994.

REIS FILHO, Daniel Aarão. Versões e ficções: a luta pela apropriação da memória. In. REIS FILHO, Daniel Aarão et alli. Versões e ficções: o seqüestro da história... São Paulo: Fundação Perseu Abramo, 1997.

RIDENTI, Marcelo. Que história é essa? In. REIS FILHO, Daniel Aarão et alli. Versões e ficções: o seqüestro da história. São Paulo: Fundação Perseu Abramo, 1997.

WALLERSTEIN, Immanuel. Após o liberalismo: em busca da reconstrução do mundo. Petrópolis, Vozes, 2002. 